\title{
Hình thức sinh sản, đặc điểm hình thái và cấu trúc mô học của tuyến sinh dục cá bống trứng Eleotris melanosoma ở ven biển Sóc Trăng
}

\author{
La Hoàng Trúc Ngân, Đinh Minh Quang* \\ Truoòng Đại học Cần Tho; khu II, Đuờng 3/2, Phuờng Xuân Khánh, Quận Ninh Kiều, Cần Tho, Việt Nam
}

Nhận ngày 12 tháng 6 năm 2017

Chỉnh sửa ngày 12 tháng 7 năm 2017; Chấp nhận đăng ngày 18 tháng 9 năm 2017

\begin{abstract}
Tóm tắt: Nghiên cứu này được thực hiện ở vùng ven biển Sóc Trăng nhằm cung cấp thông tin hữu ích về hình thức sinh sản, hình thái và cấu trúc mô học của noãn sào và tinh sào và sự phát triển của noãn bào và tinh bào ứng với từng giai đoạn phát triển của tuyến sinh dục để làm cơ sở cho khai thác bền vững nguồn lợi cá bống trứng Eleotris melanosoma - một trong những loài cá có vai trò kinh tế ở khu vực nghiên cứu. Kết quả phân tích 65 mẫu cá ( 28 cá cái và 37 cá đực) thu được vào mùa mưa và mùa khô cho thấy loài này thuộc nhóm cá đẻ tập trung thành từng đợt trong mùa sinh sản (tháng 9 đến tháng 11) do noãn sào và tinh sào ở giai đoạn trưởng thành và chín chứa chủ yếu noãn bào và tinh bào thời kỳ 4 và 5 . Những kết quả này không chỉ bổ sung dẫn liệu về đặc điểm sinh học sinh sản của loài này mà còn là cơ sở cho việc đề xuất thời gian đánh bắt phù hợp nhằm đảm bảo phát triển bền vững nguồn lợi của loài này ở khu vực nghiên cứu.
\end{abstract}

Tù khóa: Eleotris melanosoma, hình thức sinh sản, mùa sinh sản, Sóc Trăng.

\section{1. Đặt vấn đề}

Cá bống trứng Eleotris melanosoma (Bleeker, 1853) là một loài cá nhỏ và thịt ngon, có khả năng chịu được điều kiện thiếu oxy, phân bố ở Thái Lan, Borneo và Việt Nam [1, 2]. Cá bống trứng được biết đến như một loài cá đặc sản, thường xuất hiện trên các sông và có thể đẻ trứng quanh năm (chủ yếu từ tháng 4 đến tháng 6) [3]. Cá bống trứng thuộc nhóm cá ăn động vật, với thành phần thức ăn chủ yếu gồm 5 nhóm: phiêu sinh thực vật, giáp xác, cá con, phiêu sinh động vật và thân mềm [4].

\footnotetext{
* Tác giả liên hệ. ĐT.: 84-907256705

Email: dmquang@ctu.edu.vn

https://doi.org/10.25073/2588-1140/vnunst.4490
}

Sóc Trăng là khu vực có hệ thống sông ngòi chằng chịt với hai cửa sông lớn Trần Đề và Định An. Nơi đây chịu ảnh hưởng của thủy triều ngày lên xuống 2 lần (bán nhật triều) với mực thủy triều dao động khoảng 0,4-1 m [5]. Trong những năm gần đây, cá bống trứng trở thành một trong những món ăn đặc sản của tỉnh Sóc Trăng. Với tiềm năng có thể trở thành đối tượng kinh tế có giá trị cao trong thời gian sắp tới, cá bống trứng đang được quan tâm nghiên cứu. Tuy nhiên, các đề tài nghiên cứu chủ yếu tập trung về đặc điểm hình thái ngoài, môi trường phân bố [1, 6-8], đặc điểm dinh dưỡng mùa vụ sinh sản và sức sinh ở lưu vực sông Hậu [3, 4]; trong khi đó, đặc điểm sinh học sinh sản như sự phát triển của tuyến sinh dục và tế 
bào sinh dục qua từng giai đoạn cũng như là hình thức sinh sản của loài này vẫn chưa được biết đến. Chính những đặc điểm này sau khi được làm rõ sẽ là cơ sở cho việc xây dựng chiến lược khai thác hợp lý nguồn lời của loài này ở khu vực nghiên cứu cũng như là cơ sở cho việc nghiên cứu sinh sản nhân tạo chúng. Với những lý do trên, nghiên cứu này được thực hiện.

\section{Phương tiện và phương pháp nghiên cứu}

\subsection{Thời gian và địa điểm nghiên cứu}

Mẫu cá bống trứng được thu 4 đợt ở mùa mưa (tháng 6 đến tháng 12) và 2 đợt ở mùa khô (tháng 1 đến tháng 5) từ tháng tháng 6 năm 2016 đến tháng 5 năm 2017 ở khu vực ven biển tỉnh Sóc Trăng (Hình 1).

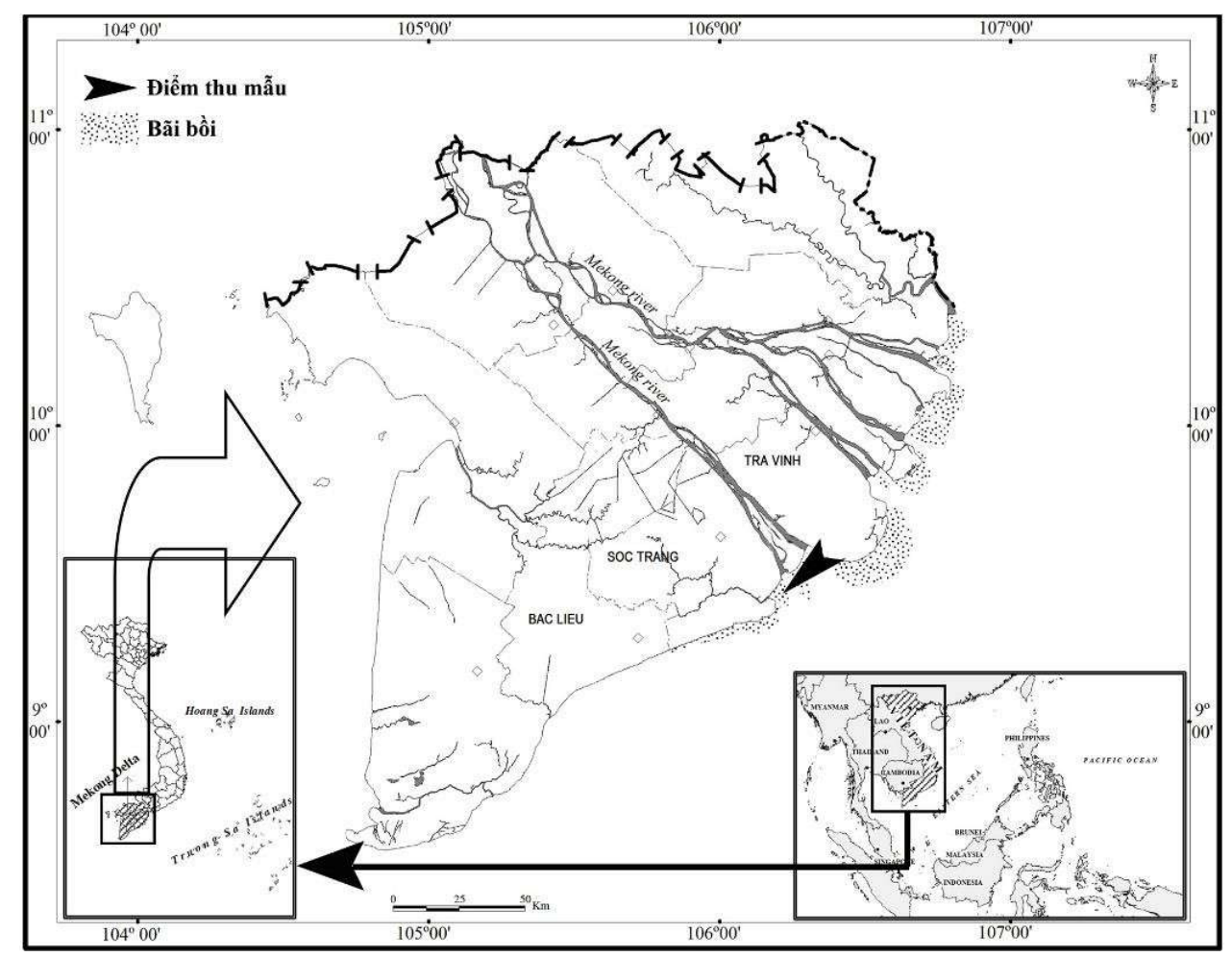

Hình 1. Bản đồ khu vực nghiên cứu (Dấu mũi tên: Điểm thu mẫu).

\subsection{Phuoong pháp thu mẫu, định loại và cố định mẫu}

Mẫu cá bống trứng được thu trực tiếp bằng lưới đáy với mắt phần đục $2 \mathrm{a}=1,5 \mathrm{~cm}$. Mẫu cá được thu ngẫu nhiên với nhiều kích cỡ khác nhau. Sau khi thu mẫu, mẫu cá sẽ được cố định trong dung dịch formol $10 \%$ và vận chuyển về phòng thí nghiệm Động vật, Bộ môn Sư phạm Sinh học, Khoa Sư phạm, Trường Đại học Cần Thơ dựa theo phương pháp nghiên cứu của Dinh Minh Quang (2015) [9].

\subsection{Phương pháp phân tích và xử lý số liệu}

Ở phòng thí nghiệm, mẫu cá được định loại dựa theo mô tả bởi Nguyễn Văn Hảo (2005) [8] và Trần Đắc Định và nnk. (2013) [1]. Mẫu cá sau đó được xác định giới tính dựa vào đặc điểm hình thái của gai sinh dục (hình tam giá nhọn ở cá đực và oval ở cá cái), đo chiều dài tổng $(\mathrm{TL}, 0,1 \mathrm{~cm})$ và xác định khối lượng $(\mathrm{W}$, $0,01 \mathrm{~g}$ ) trước khi giải phẫu để lấy tuyến sinh dục. Các giai đoạn phát triển tuyến sinh dục được xác định dựa theo 6 bậc thành thục sinh dục của cá được mô tả bởi Nikolsky (1963) [10] 
và cố định trong dung dịch formol $4 \%$ để thực hiện tiêu bản mô học.

Tiêu bản hiển vi cố định tuyến sinh dục cá bống trứng được thực hiện dựa trên phương pháp nhuộm màu kép của Carleton và nnk. (1980) [11] và dựa trên quy trình thực hiện tiêu bản hiển vi cố định tuyến sinh dục cá kèo vảy to Parapocryptes serperaster [12]. Các giai đoạn phát triển của tế bào trứng và tế bào tinh được xác định dựa theo 5 bậc phát triển được mô tả bởi Bùi Lai và nnk. (1985) [13]. Hình thức sinh sản của cá được xác định dựa vào phương pháp nghiên cứu của Miller (1984) [14].

\section{Kết quả và thảo luận}

\section{1. Đặc điểm hình thái và mô học của noãn sào}

Giai đoạn I: Noãn sào có kích thước nhỏ, dạng hai sợi nhỏ, dài và có tiết diện hơi tròn, màu trắng trong (Hình $2 \mathrm{a}$ ). Quan sát tiêu bản mô học dễ dàng thấy được noãn nguyên bào có nhân to tròn, chứa nhiều nhiễm sắc thể, nhân chiếm tỉ lệ lớn so với tế bào (Hình $3 \mathrm{a}$ ). Đường

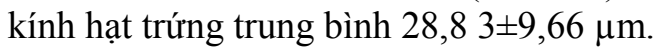

Giai đoạn II: Kích thước noãn sào lớn hơn so với giai đoạn I, dài, chưa quan sát được hạt trứng dưới kính lúp (Hình $2 \mathrm{~b}$ ). Các noãn bào thời kỳ II chiếm ưu thế về số lượng trong noãn sào, chúng có kích thước lớn hơn các noãn nguyên bào ở thời kỳ $\mathrm{I}$, có hình elip hoặc đa giác, tỉ lệ thể tích nhân so với tế bào giảm xuống (Hình 3b).

Giai đoạn III: Noãn sào tăng nhanh về kích thước, trên bề mặt xuất hiện các mạch máu nhỏ. Màu sắc vàng nhạt, quan sát được các hạt trứng (Hình $2 \mathrm{c}$ ). Ở giai đoạn này, noãn bào chuyển từ sinh trưởng sang tích lũy nên có sự gia tăng nhanh về kích thước, xuất hiện các không bào không bắt màu thuốc nhuộm, các hạt lipit và hạt noãn hoàng, nhân lớn. Noãn bào thời kỳ III chiếm ưu thế (Hình 3c).

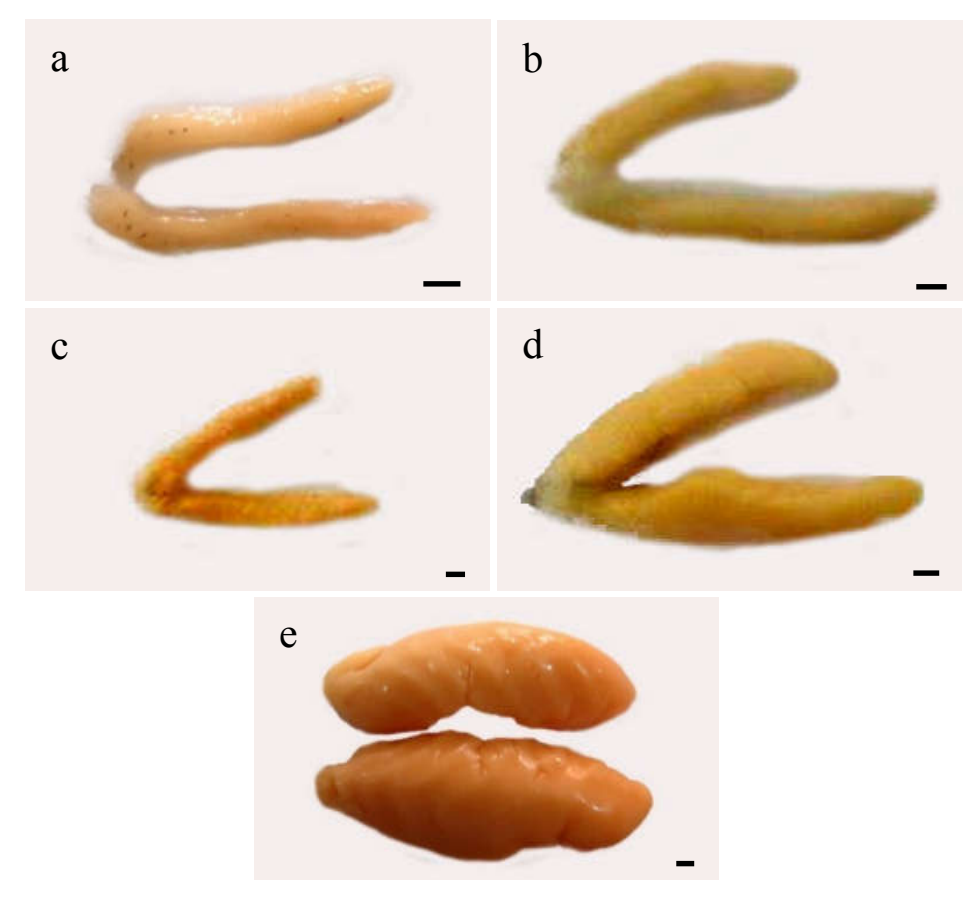

Hình 2. Hình thái ngoài của noãn sào cá bống trứng

( $a, b, c, d, e$ lần lượt là các giai đoạn của noãn sào $I, I I, I I I, I V$ và $V$; thước tỉ lệ $1 \mathrm{~mm}$ ). 
Giai đoạn IV: Noãn sào có kích thước lớn, bắt đầu có sự phân thùy, nhiều mạch máu phân bố trên bề mặt của noãn sào. Màu sắc vàng nhạt, có thể quan sát rõ các hạt trứng (Hình $2 \mathrm{~d}$ ). Noãn bào giai đoạn này có kích thước lớn nhất và đạt cực đại, hạt noãn hoàng tăng nhanh về kích thước và số lượng, nhân nhỏ lại. Tế bào chất xen giữa không bào và hạt noãn hoàng, không bào nằm rải rác khắp noãn bào (Hình $3 \mathrm{~d}$ ).
Giai đoạn $\mathrm{V}$ : Noãn sào có kích thước lớn nhất, phân thùy rõ ràng, có màu vàng đậm. Vách mỏng, mềm nhão, các hạt trứng căng tròn và tách rời nhau (Hình $2 \mathrm{e}$ ). Noãn bào chứa nhiều hạt lipit trộn lẫn với noãn hoàng, nhân rất nhỏ hoặc không quan sát được nhân. Noãn bào thời kỳ $\mathrm{V}$ chiếm ưu thế, chúng tách rời nhau chuẩn bị cho sự rụng trứng (Hình 3e).

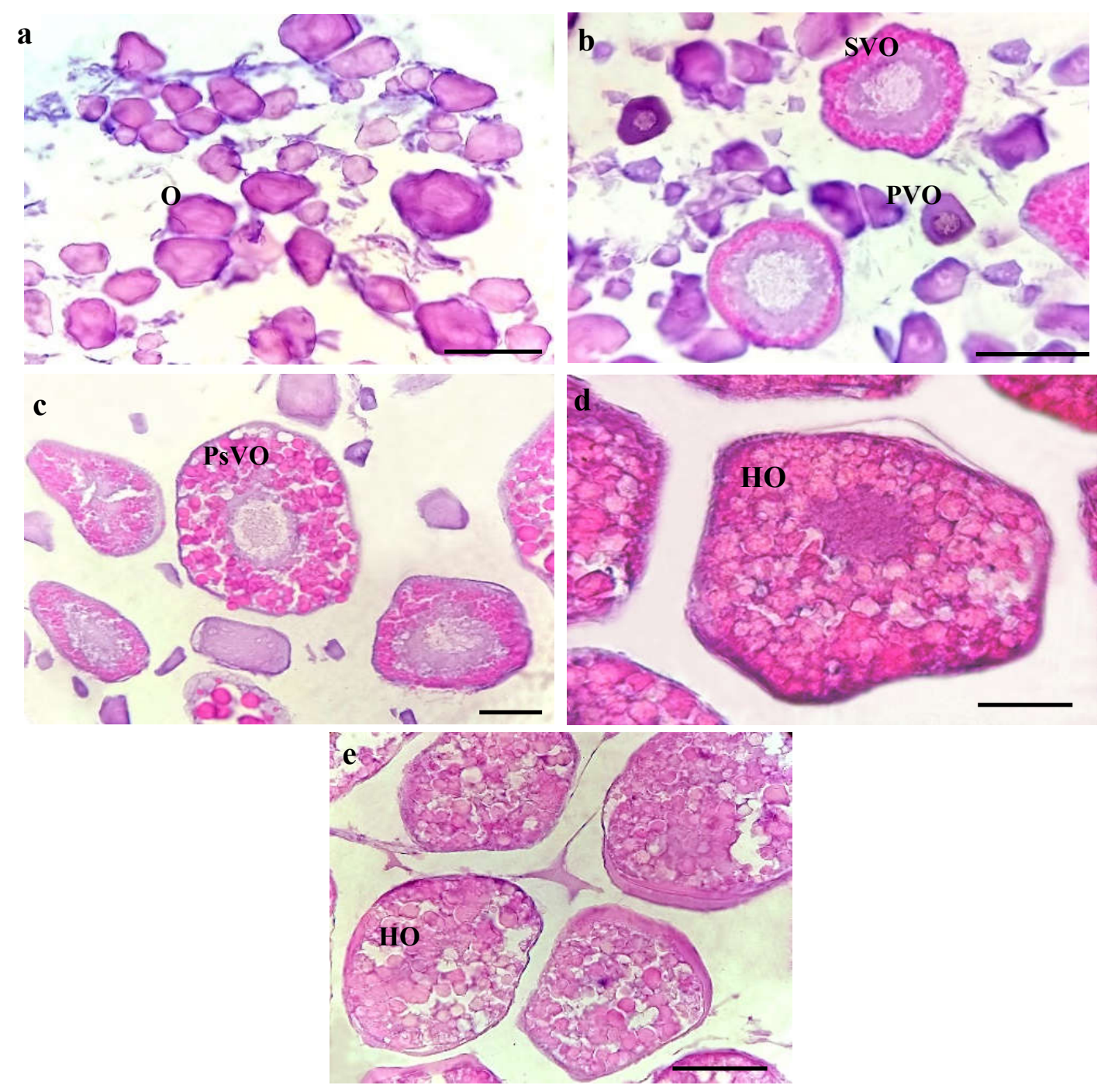

Hình 3. Lát cắt ngang qua noãn sào của cá bống trứng

$(\mathrm{a}, \mathrm{b}, \mathrm{c}, \mathrm{d}, \mathrm{e}$ lần lượt là noãn sào giai đoạn $\mathrm{I}, \mathrm{II}, \mathrm{III}, \mathrm{IV}$ và $\mathrm{V}$; Tế bào mầm $(\mathrm{GC})$, noãn nguyên bào $(\mathrm{O})$, noãn bào sơ cấp $(\mathrm{PO})$, noãn bào thời kỳ $1(\mathrm{PVO})$, noãn bào thời kỳ $2(\mathrm{SVO})$, noãn bào thời kỳ $3(\mathrm{PsVO})$, noãn bào trưởng thành $(\mathrm{HO})$; thước tỉ lệ $50 \mu \mathrm{m})$. 
Sự phát triển và cấu trúc mô học noãn sào cá bống trứng cũng giống với cá bống sao Boleophthalmus boddarti [15] cá kèo vảy to Parapocryptes serperaster [12] và cá bống trân Butis butis [16]. Các noãn bào đều trải qua các quá trình biến đổi phức tạp và tuân theo quy luật chung. Từ một noãn nguyên bào qua phân chia nguyên nhiễm tạo nên noãn bào 1 , khi noãn bào đạt kích thước nhất định thì tiến hành phân chia giảm phân 1 để tạo nền noãn bào 1 và thể cực 1 . Ở giai đoạn cuối của giảm phân 1 , noãn bào 1 tích luỹ noãn hoàng và đạt kích thước cực đại (thời kỳ IV). Đến giai đoạn chín muồi, trứng rụng và sẵn sàng thụ tinh, sau giảm phân 2 tạo nên noãn bào 2 và thể cực 2 , từ 1 noãn nguyên bào sau phân chia cho 1 tế bào trứng và 2 thể cực. Noãn bào tiếp tục trải các thời kỳ phát triển, bắt đầu một chu kỳ mới.

Ở nghiên cứu này, noãn bào thời kỳ 4 và 5 chỉ phát hiện được trong noãn sào ở các tháng 9,10 và 11 . Ở noãn sào giai đoạn $\mathrm{V}$, noãn bào thời kỳ 5 chiếm ưu thế, ít phát hiện các noãn bào thời kỳ $1,2,3$; điều này cho thấy có khả năng cá bống trứng ở khu vực ven biển tỉnh Sóc Trăng là loại cá đẻ một đợt trong mùa sinh sản. Nhận định này có sự khác biệt so với nghiên cứu trước của Võ Thành Toàn \& Trần Đắc Định (2014) [3]. Hai tác giả cho rằng cá bống trứng phân bố trên tuyến sông Hậu có mùa vụ sinh sản quanh năm, tập trung từ tháng 4 đến tháng 6. Nguyên nhân của sự khác biệt này có thể do thời gian nghiên cứu, địa điểm thu mẫu, độ mặn ở khu vực nghiên cứu cao hơn so với tuyến sông Hậu, kích cỡ cá và khối lượng tuyến sinh dục. Bên cạnh đó, các loài cá bống thuộc cùng khu vực nghiên cứu như cá bống sao $B$. boddarti [15], cá kèo vảy to $P$. serpersater [12], cá bống mít Stigmatogobius pleurostigma [17] và cá bống trân $B$. Butis [16] đều thuộc nhóm cá đẻ nhiều đợt trong năm do noãn sào ở giai đoạn $\mathrm{IV}$ và $\mathrm{V}$ chứa nhiều loại noãn bào khác nhau. Sự khác biệt này củng cố nhận định cá bống trứng thuộc nhóm cá đẻ một đợt trong mùa sinh sản.

\section{2. Đặc điểm hình thái và cấu trúc mô học của tinh sào}

Giai đoạn I: Tinh sào có dạng sợi mảnh, dẹp, nằm sát phía cột sống của thân cá. Màu sắc trắng trong, khó phân biệt đực cái bằng mắt thường (Hình 4$)$. Lát cắt ngang tinh sào chứa nhiều tinh nguyên bào tập trung thành từng cụm phân bố khắp tinh sào. Xen kẽ giữa các cụm tinh nguyên bào là các mô liên kết dày đặc, không quan sát được ống dẫn tinh (Hình $5 \mathrm{a}$ ).
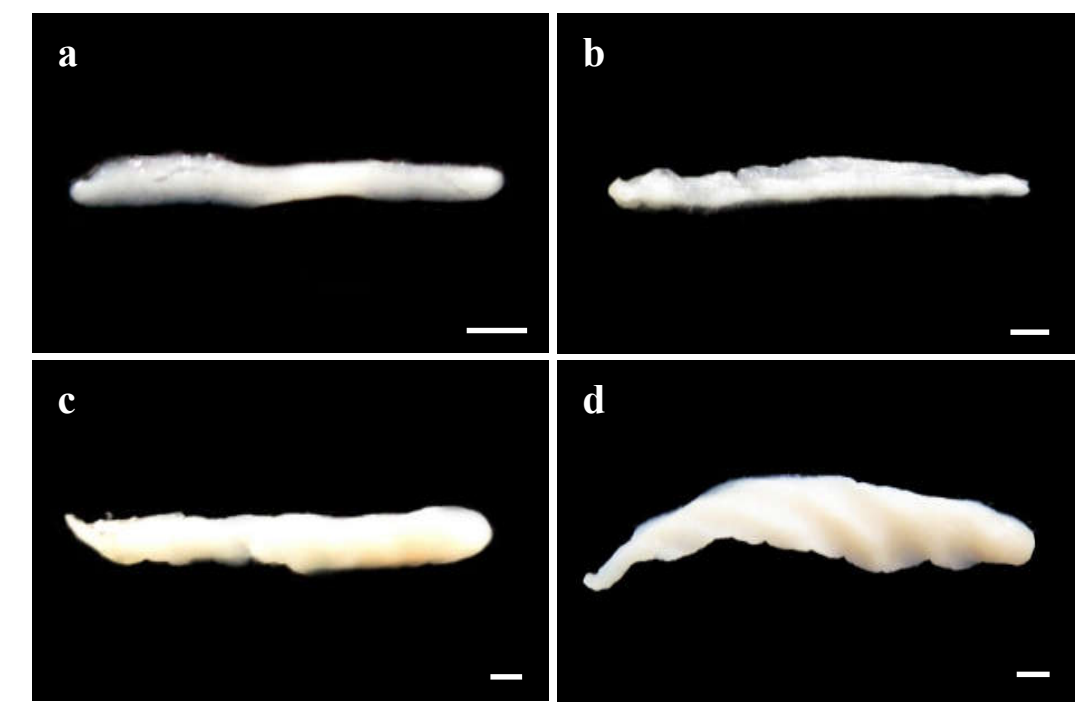

Hình 4. Hình thái ngoài của tinh sào cá bống trứng (a, b, c, d lần lượt là tinh sào giai đoạn I, II, III và IV; thước tỉ lệ 1mm). 
Giai đoạn II: Tinh sào có kích thước lớn hơn, dài và dẹp, có sự phân thùy nhỏ, màu trắng (Hình $4 b)$. Tinh nguyên bào ở giai đoạn này phát triển thành tinh bào cấp 1 , có kích thước nhỏ hơn tinh nguyên bào, sắp xếp đan xen giữa các cụm tinh nguyên bào; ngoài ra còn có sự phân bố rải rác của các tinh bào cấp 2 (Hình $5 b$ ).

Giai đoạn III: Tinh sào gia tăng kích thước, dẹp, phân thùy rõ, màu sắc trắng ngà. Mô liên kết trong tinh sào mỏng lại (Hình $4 \mathrm{c}$ ). Tinh nguyên bào giảm xuống rõ rệt, thay thế bằng sự xuất hiện dày đặc của tinh bào cấp 1 , tinh bào cấp 2 và tinh tử (Hình $5 \mathrm{c}$ ).

Giai đoạn IV: Tinh sào có kích thước lớn, bề mặt tinh sào căng phồng và có sự gợn sóng, màu sắc trắng sữa. Mô liên kết ở giai đoạn này rất mỏng (Hình $4 \mathrm{~d})$. Tinh sào có sự phân thùy rõ rệt, các ống dẫn tinh chứa đầy tinh trùng đã chín muồi, phân bố thành từng cụm lớn trong các thùy (Hình $5 \mathrm{~d}$ ).

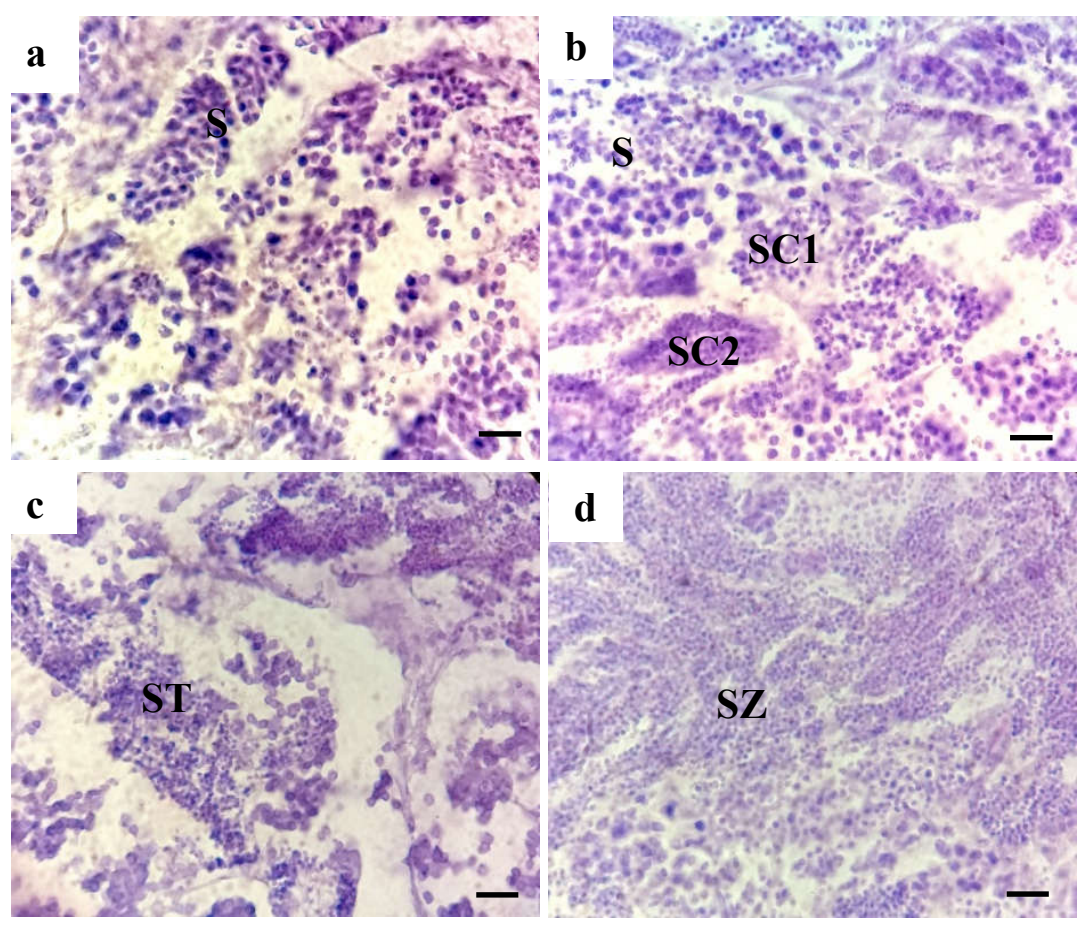

Hình 5. Lát cắt ngang qua tinh sào cá bống trứng

$(\mathrm{a}, \mathrm{d}, \mathrm{c}, \mathrm{d}$ lần lượt là tinh sào giai đoạn I, II, III và IV; Tinh nguyên bào $(\mathrm{S})$, tinh bào thời kỳ 1 (SC1), tinh bào thời kỳ $2(\mathrm{SC} 2)$, tinh tử $(\mathrm{ST})$ và tinh trùng $(\mathrm{SZ}))$

Tương tự như sự phát triển của noãn sào, tinh sào cũng trải qua các giai đoạn phát triển như như cá bống sao $B$. boddarti [15], cá kèo vảy to $P$. serpersater [12], cá bống mít Stigmatogobius pleurostigma [17] và cá bống trân $B$. Butis [16]. Từ tinh nguyên bào phân chia nguyên nhiềm để tăng số lượng, sau đó tinh bào lớn lên thành tinh bào 1 . Ở giai đoạn tiếp theo, tinh bào 1 sẽ phân chia giảm nhiềm tạo tinh bào 2, phân chia giảm nhiễm lần 2 tạo nên tinh tử và biệt hóa thành tinh trùng.
Trong số mẫu thu được trong thời gian nghiên cứu chưa phát hiện được noãn sào ở giai đoạn VI và tinh sào ở giai đoạn $\mathrm{V}$ và VI nên đặc điểm cấu trúc mô học ở những giai đoạn này chưa được mô tả. Người dân nên hạn chế khai thác cá vào khoảng thời gian từ tháng 9 đến tháng 11 (mùa sinh sản) nhằm đảm bảo khai thác bền vững nguồn lợi của loài này ở khu vực nghiên cứu. 


\section{Kết luận}

Trong quá trình thành thục sinh dục, noãn sào và tinh sào của cá bống trứng có sự thay đổi về kích thước, màu sắc và đặc điểm hình dạng. Qua lát cắt ngang tuyến sinh dục của cá bống trứng, quan sát được noãn bào và tinh bào có sự biến đồi về các thành phần tế bào để phù hợp với sự thành thục sinh dục. Tuyến sinh dục của cá bống trứng ở giai đoạn trưởng thành và chín xuất hiện từ tháng 9 đến tháng 11 và chứa noãn bào và tinh bào thời kỳ 4 và 5 . Điều này cho thấy cá bống trứng là loài cá đẻ một đợt trong mùa vụ sinh sản (tháng 9 đến tháng 11).

\section{Lời cảm ơn}

Chúng tôi xin chân thành cảm ơn Bộ Giáo dục \& Đào tạo đã tài trợ kinh phí và anh Miền (ngư dân) đã hỗ trợ thu mẫu cho nghiên cứu này (Mã số: B2015-16-49).

\section{Tài liệu tham khảo}

[1] Trần Đắc Định, Koichi, S., Nguyễn Thanh Phương, Hà Phước Hùng, Trần Xuân Lợi, Mai Văn Hiếu \& Kenzo, U., Mô tả định loại cá Đồng bằng sông Cửu Long, Việt Nam, Nxb Đại học Cần Thơ, Cần Thơ, 2013.

[2] Froese, R. \& Pauly, D., FishBase, World Wide Web electronic publication, 2017, truy cập ngày 10/06/2017. www.fishbase.org

[3] Võ Thành Toàn \& Trần Đắc Định, Một số đặc điểm sinh học sinh sản cá bống trứng (Eleotris melanosoma) phân bố dọc theo sông Hậu, Tạp chí Khoa học Đại học Cần Thơ, Thủy sản (2014) 115122.

[4] Võ Thành Toàn, Trần Đắc Định \& Dương Thị Hoàng Oanh, Nghiên cứu đặc điểm dinh dưỡng của cá bống trứng (Eeleotris melanosoma Bleeker, 1853) phân bố dọc theo tuyến sông Hậu, Hội nghị toàn quốc về sinh học biển và phát triển bền vững lần 2, Nxb Khoa và Kỹ thuật, 507-514, 2014.
[5] Cục thống kê tỉnh Sóc Trăng, Niên giám thống kê Sóc Trăng 2015, Nxb Thống kê, Sóc Trăng, 2016.

[6] Mai Đình Yên, Nguyễn Văn Trọng, Nguyễn Văn Thiện, Lê Hoàng Yến \& Hứa Bạch Loan, Định loại cá nước ngọt Nam bộ, Nxb Khoa học và Kỹ thuật, Hà Nội, 1992.

[7] Trương Thủ Khoa \& Trần Thị Thu Hương, Định loại cá nước ngọt vùng Đồng bằng sông Cửu Long, Tủ sách Đại học Cần Thơ, Cần Thơ, 1993.

[8] Nguyễn Văn Hảo, Cá nước ngọt Việt Nam, Nxb Nông nghiệp, Hà Nội, 2005.

[9] Dinh Minh Quang, Preliminary study on dietary composition, feeding activity and fullness index of Boleophthalmus boddarti in Mekong Delta, Vietnam, Tap chi Sinh hoc, 37 (2015) 252-257.

[10] Nikolsky, G. V., Ecology of fishes, Academic Press, London, United Kingdom, 1963.

[11] Carleton, H. M., Drury, R. A. B. \& Wallington, E., Carleton's Histological Technique, Oxford University Press, London, United Kingdom, 1980.

[12] Dinh Minh Quang, Qin, J. G., Dittmann, S. \& Tran Dac Dinh, Reproductive biology of the burrow dwelling goby Parapocryptes serperaster, Ichthyological Research, 63 (2016) 324-332.

[13] Bùi Lai, Nguyễn mộng Hùng, Nguyễn Quốc Khang, Lê Quang Long \& Mai Đình Yên, Cơ sở sinh lý sinh thái cá, Nxb Nông nghiệp, Hà Nội, 1985.

[14] Miller, P. J., The topology of gobioid fishes, In: G. W. Potts, R. J. Wootton (ed) $\wedge$ (eds) Fish reproduction: Strategies and Tactics, Academic Press, Orlando, London, United Kingdom, pp. 119-153, 1984

[15] Dinh Minh Quang, Nguyen Thi Tra Giang \& Nguyen Thi Kieu Tien, Reproductive biology of the mudskipper Boleophthalmus boddarti in Soc Trang, Tap chi Sinh hoc, 37 (2015) 362-369.

[16] Dinh Minh Quang \& Le Thi My Tien, Reproductive traits of the Duckbill sleeper Butis butis (Hamilton, 1822), Zoological Science, Accepted (2017).

[17] Đinh Minh Quang, Đặc điểm hình thái và sinh học sinh sản cá bống mít Stigmatogobius pleurostigma (Bleeker, 1849), Báo cáo đề tài nghiên cứu khoa học cấp cơ sở, Trường Đại học Cần Thơ, Cần Tho, 2016. 


\title{
Reproductive Pattern, Morphological and Histological Characteristics of Gonads of the Goby Eleotris melanosoma from the Coastline in Soc Trang
}

\author{
La Hoang Truc Ngan, Dinh Minh Quang \\ Can Tho University, Campus II, 3/2 street, Xuan Khanh Ward, Ninh Kieu District, Can Tho City, Vietnam
}

\begin{abstract}
This study was conducted in the coastline in Soc Trang to contribute useful information on reproductive pattern, morphological and histological characteristics of ovaries and testes and development of oocytes and spermatocytes per gonadal development stages of the goby Eleotris melanosoma, a commercial fish in the study area. Data analysis of 65 individuals ( 28 females and 37 males) collected during the wet and dry seasons showed that this species fall into single spawner category since ovaries and testes at the mature and ripe stages comprised stage 4 and 5 of oocytes and spermatocytes. The results not only contributed to reproductive data but also based to set suitable sampling time for sustainable exploitation the fish resources in the study region.
\end{abstract}

Keywords: Eleotris melanosoma, reprodutive pattern, spawning season, Soc Trang. 